\title{
PENERAPAN PERANGKAT LUNAK MULTIMEDIA INTERAKTIF PEMBELAJARAN AL-QUR'AN DENGAN METODE TILAWATI CABANG MALANG
}

\author{
IMPLEMENTATION OF INTERACTIVE MULTIMEDIA SOFTWARE \\ AL-QUR'AN LEARNING USING TILAWATI METHOD OF MALANG BRANCH
}

\author{
Aminudin $^{1)}$, Setio Basuki ${ }^{2)}$, Muhammad Yusuf ${ }^{3)}$ \\ 1),2) Jurusan Teknik Informatika, Universitas Muhammadiyah Malang, Malang, Indonesia \\ ${ }^{3)}$ Jurusan Tarbiyah, Fakultas Agama Islam, Universitas Muhammadiyah Malang, Malang, Indonesia \\ Email: ${ }^{1)}$ aminudin2008@umm.ac.id, ${ }^{2}$ setio_basuki@umm.ac.id, ${ }^{3)}$ muhammad.yusuf@umm.ac.id,
}

\begin{abstract}
ABSTRAK
Sistem pendidikan pada TPQ tidak seperti pada model sekolah formal dimana seluruh santri diwajibkan memulai dan menyelesaikan suatu modul belajar bersama-sama. Beberapa permasalahan yang mendasar yang di hadapi masing-masing mitra diantaranya aspek motivasi santri dan fasilitas pendukung pembelajaran dimana hampir seluruh santri di tempat mitra hanya melakukan pembelajaran ketika berada pada TPQ. Menjadi kendala bagi santri untuk mengulang kembali pelajaran atau bahkan mempersiapkan diri lebih dini untuk mempersiapkan ujian adalah bahwa tidak terdapat media alternatif selain buku teks modul Tilawati. Pada Skim Pengabdian Internal kali ini kami mengusulkan sebuah media pendukung pembelajaran Tilawati berupa aplikasi berbasis multimedia yang dapat mencocokan antara teks di dalam modul tilawati dengan suara berdasarkan modul tersebut. Diharapkan dengan adanya media pendukung pembelajaran ini dapat meningkatkan ketersediaan sarana belajar mengajar di lingkungan $T P Q$ dan dapat meningkatkan motivasi belajar santri serta dapat digunakan oleh orang awam yang berkehendak belajar Al-Qur'an tetapi terkendala masalah waktu dll. Perangkat Lunak yang akan dikembangkan menggunakan teknologi berbasis website agar dapat digunakan di mana saja dan kapan saja menggunakan koneksi internet.
\end{abstract}

Kata kunci: Perangkat Lunak, Metode Tilawati, Multimedia, $T P Q$

\section{ABSTRACT}

The education system on the TPQ is not like the formal school model where all students are required to start and complete a learning module together. Some of the fundamental problems faced by each partner include aspects of student motivation and learning support facilities where almost all students at the partner site only learn when on TPQ. Being an obstacle for students to repeat the lesson or even prepare early to prepare for the exam is that there are no alternative media other than the Tilawati module textbook. In this Internal Service Scheme we propose a Tilawati learning support media in the form of multimedia-based applications that can match text in the tilawati module with sound based on the module. It is expected that with the support of learning media can increase the availability of teaching and learning facilities in the TPQ environment and can increase student learning motivation and can be used by lay people who want to study the Qur'an but are constrained by time problems etc. Software that will be developed using website-based technology so that it can be used anywhere and anytime using an internet connection.

Keywords: Software, Tilawati Method, Multimedia, TPQ

Submited : 29 November 2018 Revision : 12 Maret 2019 Accepted:16 Maret 2019

\section{PENDAHULUAN}

Taman Pendidikan Al-Quran (TPQ) merupakan sebuah lembaga pendidikan untuk mendidik santri agar dapat membaca Al-Quran sesuai dengan aturan yang berlaku. Pembelajaran TPQ tidak terdapat batas usia untuk menjadi santri, maka tidak heran jika terdapat santri yang masih berusia sangat muda (4 tahun) telah menyelesaikan seluruh modul pembelajaran, dan santri yang lebih tua ( 8 tahun) yang baru memulai mempelajari AlQuran. Untuk dapat dikatakan lulus, santri 
diwajibkan mengikuti tes baik yang diuji oleh pengajar maupun kepala TPQ untuk setiap modul. Salah satu teknik yang digunakan untuk melakukan pengajaran adalah Tilawati.

Metode Tilawati ini terdiri dari 6 buah modul/jilid dan dipilih dengan alasan mengharuskan pengucapan secara baik dan benar. Tilawati menawarkan suatu sistem pembelajaran Al-Qur'an yang yang mudah, efektif dan efesien demi mencapai kualitas bacaan, pemahamanan dan implementasi Al Qur'an. Metode Tilawati menggabungkan metode pengajaran secara klasikal dan privat secara seimbang sehingga pengelolaan kelas lebih efektif. Ustadz atau ustadzah dapat mengajari santri hingga 15-20 orang tanpa mengurangi kualitas. Target kualitas yang ingin dicapai dalam pembelajaran Metode Tilawati ini adalah santri menguasai bacaan Al quran dengan baik dan benar, yang meliputi (1) Fashohah (praktek), meliputi kaidah : Al waqfu wal Ibtida'; Muroatul huruf wal harokat; Muroatul huruf wal kalimat, (2) Tajwid (Teori dan Praktek), meliputi : Makhorijul huruf; Ahkamul huruf; Shifatul huruf; Ahkamul Mad wal Qosr, (3) Ghorib dan Musykilat (Teori dan Praktek), (4) Suara dan Irama (Praktek), meliputi Kualitas vokal dan penguasaan lagu ROST. Kelebihan metode ini yaitu:(1) Menyeimbangkan pendekatan pembelajaran secara klasikal dan individual, (2) Metode ini disusun secara praktis sehingga mudah dipelajari, (3) Menekankan pada kemampuan peserta didik untuk dapat membaca al-Qur'an secara tartil, dan (4) Menggunakan variasi lagulagu tilawah dalam membaca al-Qur'an sehingga tidak membosankan.

Mitra yang kami jadikan sebagai objek pengabdian merupakan TPQ di kawasan Kota Malang yang keduanya menggunakan metode Tilawati untuk mendidik para santri. TPQ Babus Salam saat ini memiliki 200 santri dengan rentang umur dari 4 sampai 10 tahun, dengan jumlah pengajar sebanyak 10 . Sedangkan TPQ Manba'ul Huda memiliki 100 santri dengan rentang usia antara 4 dan 12 tahun, dengan pengajar berjumlah 8 . Rata-rata waktu yang diperlukan santri untuk menyelesaikan seluruh modul adalah 1 tahun 6 bulan untuk TPQ Babus Salam dan 1 tahun 10 bulan untuk TPQ Manba'ul Huda.Namun demikian, terdapat pola yang sama yaitu mayoritas santri $(>60 \%)$ berada pada rentang waktu yang lama untuk menyelesaikan seluruh modul. Pembelajaran Tilawati di kedua mitra diselenggarakan di ruangan-ruangan yang terletak di dalam masjid. Sarana belajar yang digunakan selama di dalam kelas yaitu buku modul Tilawati untuk pengajar dan santri serta beberapa white board.

Terdapat beberapa faktor yang mempengaruhi kecepatan pemahaman terhadap sebuah materi belajar yaitu tingkat kecerdasan, motivasi santri, metode pengajaran, dan fasilitas pembelajaran. Situasi yang dihadapi oleh kedua mitra adalah pada aspek motivasi santri dan fasilitas pendukung pembelajaran. Hampir seluruh santri di tempat mitra hanya melakukan pembelajaran ketika berada pada TPQ. Yang menjadi kendala bagi santri untuk mengulang kembali pelajaran atau bahkan mempersiapkan diri lebih dini untuk mempersiapkan ujian adalah bahwa tidak terdapat media alternatif selain buku teks modul Tilawati.

Selain itu santri tidak memiliki fasilitas untuk mengulang pembelajaran yang telah dilakukan di TPQ atau mengecek bentuk bacaan yang dia baca sudah benar atau salah hal ini dikarenakan tidak semua orang tua santri dapat mengkoreksi bacaan tersebut atau dalam bahasa santri nya 'nyemak'. Permasalahan selanjutnya terkait dengan motivasi santri yang rendah untuk mempelajari metode Tilawati. Buku panduan yang dimiliki santri tidak terlalu dapat meningkatkan minat belajar santri. Harapan mitra adalah terdapat suatu media belajar alternatif bagi santri TPQ untuk dapat mengakselerasi kemampuan baca Al-Quran. Media yang diinginkan adalah berupa media interaktif yang dikembangkan dengan metode tertentu yang dapat menarik minat santri untuk pembelajaran dan pemantapan metode Tilawati secara mandiri. Selain dapat digunakan oleh santri, media alternatif ini dapat pula dimanfaatkan oleh anak belum menjadi santri TPQ atau bahkan orang dewasa yang hendak mempelajari teknik baca Al-Quran dengan metode Tilawati. Dengan demikian, seluruh proses untuk menyelesaikan seluruh modul Tilawati dapat di reduksi.

Berdasarkan analisa situasi tersebut, kami dari tim Pengabdian mengusulkan suatu aplikasi berbasis multimedia interaktif untuk mengakomodasi kebutuhan dari beberapa masalah yang telah diuraikan diatas. Aplikasi 
yang akan dibangun melibatkan beberapa komponen media seperti animasi, gambar, dan suara. Beberapa fungsi yang dapat diperoleh dari aplikasi ini adalah (1) ekstraksi inti dari metode Tilawati setiap modul, (2) Mind Mapping dari keseluruhan materi yang disajikan untuk setiap modul yang dicocokan dengan suara (3) panduan pelafalan hurus dan teks. PL yang diusulkan adalah aplikasi bergerak pada telepon selular maupun tablet $p c$ dan berbasis online agar dapat digunakan di mana saja dan kapan saja. Berdasarkan hasil dari evaluasi yang dilakukan oleh mitra, terdapat beberapa permasalahan yang di hadapi yaitu:

- Santri hanya melakukan pembelajaran ketika berada dilokasi TPQ dan tidak adanya alternatif pembelajaran setelah pembelajaran dari TPQ.

- Perbedaan jenjang usia yang belajar di lembaga TPQ, misalnya terdapat santri yang masih berusia sangat muda sudah menyelesaikan seluruh modul, namun terdapat usia yang lebih tua baru memulai belajar membaca Al-Quran.

- Banyak orang awam yang akan belajar AlQur'an tetapi banyak sekali kendala yang di hadapi misalnya malu karena terlambat untuk belajar Al-Qur'an sejak dini, tidak punya waktu untuk menghadap ustadz Tilawati dll.

- Perbandingan guru dan santri yang kurang memadai mempengaruhi kecepatan santri menguasai materi. Sehingga butuh media pendukung untuk belajar mandiri bagi santri.

\section{METODE KEGIATAN}

Secara keseluruhan tahapan proses yang akan dilakukan pada usulan pengabdian ini dijelaskan pada Gambar 1. Sedangkan metode yang dilakukan dalam pelaksanaan usulan pengabdian ini meliputi tiga pendekatan yaitu Rekayasa Perangkat Lunak (RPL), komunikasi dua arah dan pelatihan.

\subsection{Pengembangan Perangkat Lunak}

Perangkat lunak yang akan diterapkan pada pengabdian merupakan hasil penelitian yang disamakan dan didasarjan dari permasalahan yang dihadapi oleh mitra. Aplikasi yang diterapkan sudah dapat diakses secara bebas dengan alamat url http://www.belajar-tilawati.id. Aplikasi yang dibuat berbasis web responsive maka aplikasi tersebut dapat dibuka dari berbagai device tanpa mengubah konten ukuran aplikasi.

Perangkat lunak yang dibangun merupakan hasil mapping materi yang ada didalam buku Tilawati. Hasil mapping tersebut dicocokan dengan hasil rekaman salah satu ustadz TPQ yang menggunakan metode tilawati. Jadi intinya antara suara dari Ustadz yang kami rekam sesuai dengan huruf yang ada di dalam tampilan perangkat lunak. Untuk implementasi pencocokan tampilan huruf mapping jilid buku Tilawati dengan suara kami menggunakan teknologi web JQuery dan AJAX.

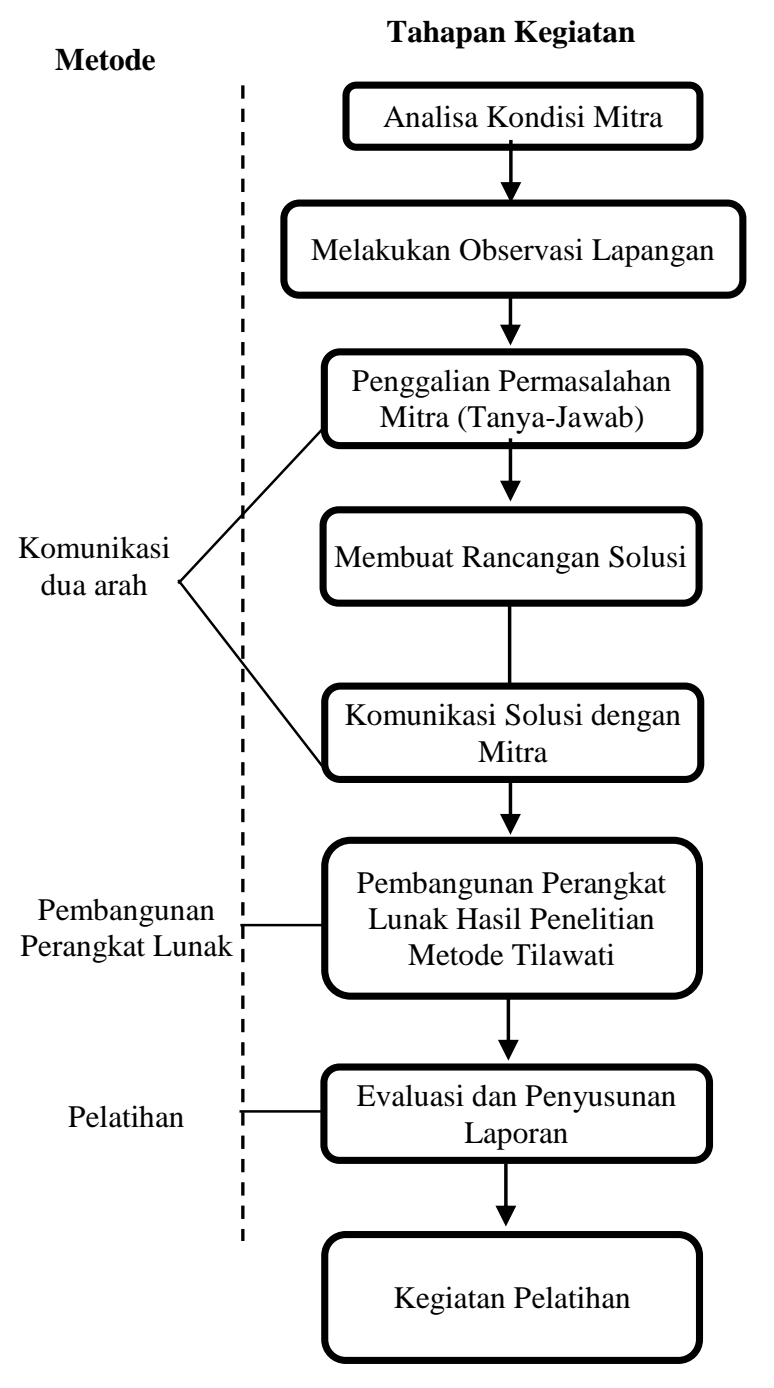

Gambar 1. Alur Metode Pelaksanaan Kegiatan 


\subsection{Komunikasi Dua Arah}

Metode Komunikasi yang dilakukan berlangsung dua arah, antara anggota tim pengabdian dan mitra. Metode komunikasi dua arah dimaksudkan untuk dapat lebih menggali permasalah mitra secara lebih obyektif, mendalam, efektif, dan efisien. Sehingga diharapkan dapat memberikan solusi yang tepat guna terhadap permasalahan yang dihadapi mitra. Komunikasi dua arah dilakukan pada saat penggalian permasalahan mitra, usulan solusi terhadap masalah mitra, dan penggalian kebutuhan mitra terhadap aplikasi yang akan dibangun.

\subsection{Pelatihan dan Training}

Pelatihan untuk memberikan panduan kepada pengguna yang dalam hal ini adalah guru TPQ, santri TPQ, dan orang tua santri. Proses ini bertujuan untuk memperkenalkan guru pada PL Perangkat Lunak Multimedia Interaktif Pembelajaran TPQ. Tahap ini memberikan pengetahuan menyeluruh tentang PL yang dibangun, fungsionalitas yang dimiliki, dan melakukan simulasi yang disesuaikan dengan kondisi nyata. Untuk melaksanakan pelatihan diperlukan kerjasama dan peran dari Tim Pengabdian Internal dengan Mitra atau pengguna.

\section{Tabel 1. Peran Tim Pengabdi dan Mitra}

\begin{tabular}{|c|c|}
\hline Tim & Peran \\
\hline $\begin{array}{l}\text { Tim } \\
\text { Pengabdi } \\
\text { UMM }\end{array}$ & 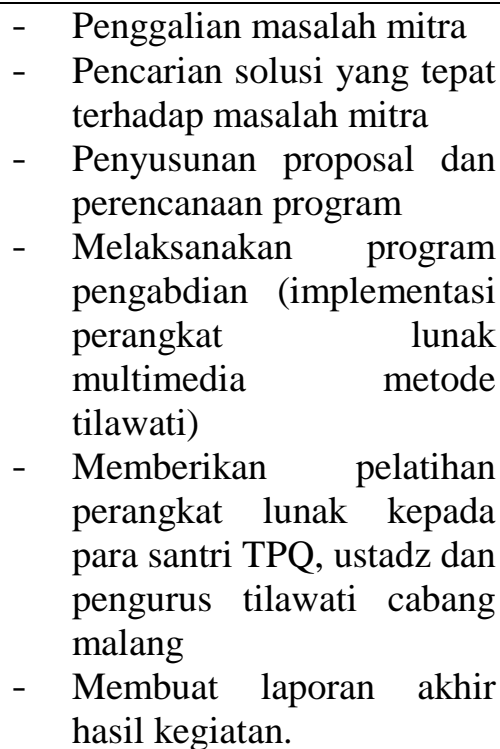 \\
\hline
\end{tabular}

\begin{tabular}{|c|c|}
\hline Tim & Peran \\
\hline Mitra & 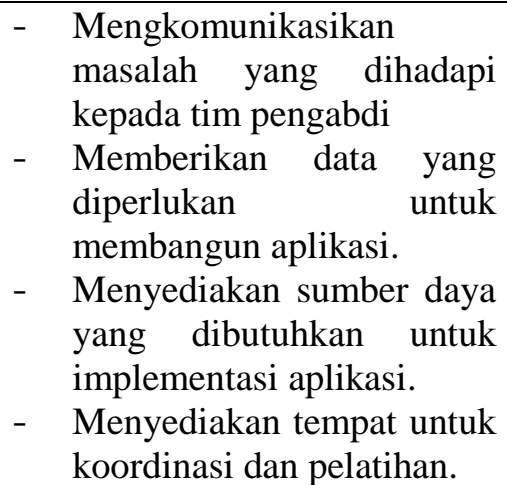 \\
\hline
\end{tabular}

\section{HASIL DAN PEMBAHASAN}

\subsection{Konsultasi dengan Kepala TPQ}

Setelah aplikasi yang dibuat dapat diselesaikan maka tahap selanjutnya adalah melakukan konsultasi dengan kepala Tilawati cabang Malang Raya untuk melakukan testing atau uji coba aplikasi berdasarkan pakar. Hal ini dilakukan untuk mengetahui kebenaran dari aplikasi yang dibuat yang didukung oleh pakar dalam bidangnya. Konsultasi ini dilakukan secara bertahap dan beberapa kali untuk membuktikan kebenaran dari aplikasi yang dibuat. Konsultasi dilakukan di Rumah Bapak Nanang Qomaruzzaman selaku Ustadz kepala TPQ Daarussalam dan sebagai salah satu Kepala Tilawati Cabang Malang Raya. Adapun bentuk pengabdian yang dilaksanakan seperti yang ditampilkan pada Diagram berikut.

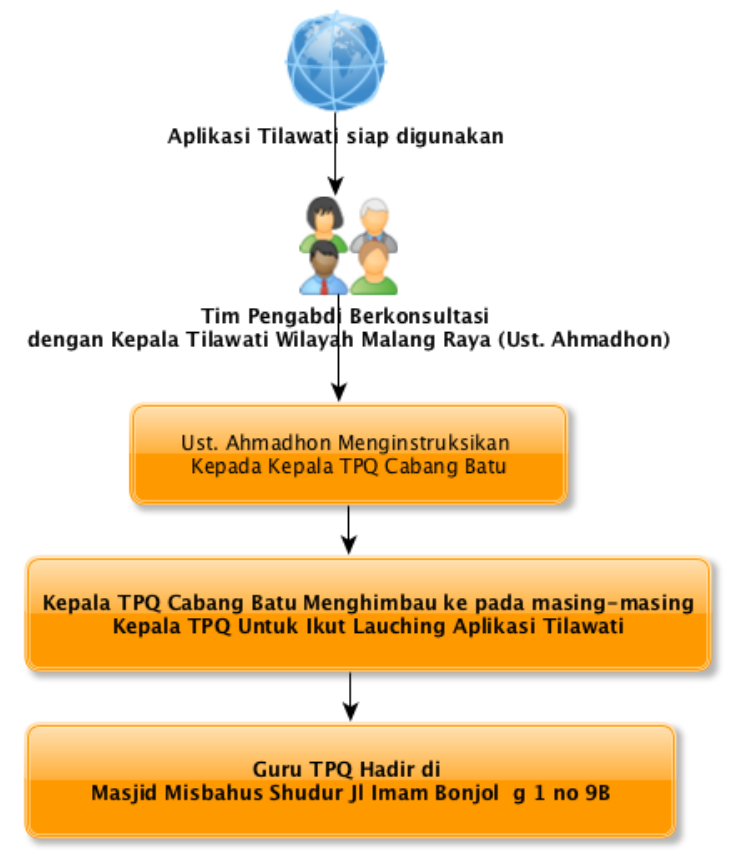

Gambar 2. Alur Pelaksaan Kegiatan Pengabdian 
Gambar 2 menunjukkan bahwa kegiatan pengabdian dilakukan secara bertahap. Dimulai dari ketika aplikasi selesai dibuat, lalu pengabdi melakukan konsultasi dengan pihak kepala TPQ Tilawati Wilayah malang secara bertahap dan dilakukan secara intensif. Kemudian setelah dikira sudah benar aplikasi yang dibuat maka kepala TPQ Wilayah Malang menginstruksikan untuk masing-masing koordinator Cabang melakukan koordinasi di dalam Lauching aplikasi belajar tilawati ini.

\subsection{Pelaksanaan Kegiatan Pelatihan}

Kegiatan sosialisasi dilakukan untuk memperkenalkan software yang telah dibangun. Kegiatan sosialiasi dihadiri 150 peserta dari berbagai perwakilan TPQ seluruh wilayah Malang Raya. Peserta sosialisasi adalah pengurus TPQ, santri, dan orang tua santri. Tempat pelaksanaan sosialisasi dilaksanakan di Masjid Misbahus Sudur, Kota Batu, mulai pukul 13.00 sampai dengan 15.00.

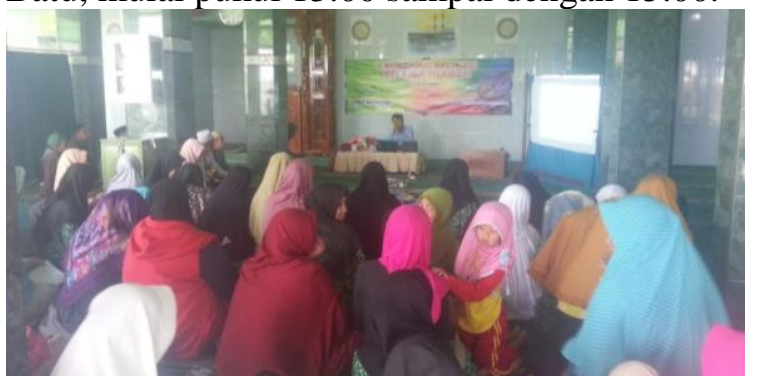

Gambar 3. Kegiatan Sosialisasi Aplikasi Belajar-Tilawati

\subsection{Evaluasi Hasil Kegiatan Pengabdian}

Setelah melalui serangkaian proses pengujian dari sisi pengembang maupun pengguna, rencana tahap selanjutnya adalah mengembangkan aplikasi belajar membaca AlQur'an berbasis mobile. Hal ini disebabkan oleh pengguna aplikasi yang lebih terbiasa menggunakan handphone daripada komputer maupun laptop. Aplikasi yang telah dibangun saat ini adalah berbasis web yang pada dasarnya masih dapat dibuka pada handphone namun sedikit mengurangi kenyamanan pada sisi antar muka.

Untuk mengakomodasi hal ini, kami merencanakan untuk mengembangkan perangkat lunak pada sistem operasi android yang terdiri dari beberapa tahap yaitu Analisa kebutuhan, perancangan, implementasi, pengujian, dan perawatan sistem. Pengujian software dilakukan melalui dua tahapan yaitu pengujian oleh pengembang yang dalam hal ini adalah kami sendiri dan pengujian oleh pengguna yaitu santri dan orang tua santri.

\section{KESIMPULAN}

Kegiatan pengabdian masyarakat ini dimaksudkan untuk memperkenalkan aplikasi belajar membaca Al-Qur'an berbasis web menggunakan metode Tilawati. Kehadiran software ini bertujuan untuk memberikan alternatif media pembelajaran bagi santri ketika berada di luar kelas. Selain itu, media alternatif ini dapat pula dimanfaatkan bagi orang tua yang hendak mempelajari cara membaca Al-Qur'an. Aplikasi Tilawati ini terdiri dari 6 buah modul/jilid yang terdiri dari teks dan suara. Mitra kami pada kegiatan pengabdian ini adalah dua TPQ di kawasan kota Malang yang keduanya menggunakan metode Tilawati untuk mendidik para santri.

Dari hasil penguijan pada kedua TPQ tersebut, peserta sosialisasi memberikan apresiasi terhadap aplikasi Tilawati. Apresiasi utamanya disampaikan karena aspek multimedia interaktif dimana pengguna tidak hanya sebatas membaca petunjuk atau tutorial cara membaca teks Al-Qur'an dengan benar, namun juga mendapat pentunjuk berupa cara pengucapanya. Untuk pengembangan dimasa yang akan datang, perlu dikembangkan aplikasi berbasis mobile untuk meningkatkan aksesbilitas penggunaan software ini. Konten yang berbasis mobile akan lebih mudah digunakan oleh santri atau orang tua yang lebih terbiasa menggunakan handphone daripada komputer maupun laptop.

\section{DAFTAR PUSTAKA}

Cahyanto. F.N., 2010, "Program Bantu Pembelajaran Perhitungan Perkalian dengan Jarimatika", Skripsi, Fakultas Teknik, Universitas Muria Kudus, Kudus

Maulana. A., 2012, "Rancang Bangun Game Edukasi Huruf Hijaiyyah pada Aplikasi Mobile", Skripsi, Fakultas Teknik, Universitas Muria Kudus, Kudus 
Aminudin, Setio Basuki, Muhammad Yusuf

Sobri. M., 2013, “Aplikasi Belajar Membaca Iqro' Berbasis Mobile", Seminar Nasional Teknologi Informasi dan Multimedia, Yogyakarta

Subaedah., 2010, "Rancang Bangun Sistem Pembelajaran Baca Al Qur'an Berbasis Multimedia", Skripsi, Fakultas Teknik, Universitas Muria Kudus, Kudus.

Triyanto. W.A., 2011, "Rancang Bangun Game Edukasi Aksara Jawa pada
Aplikasi Mobile", Skripsi, Fakultas Teknik, Universitas Muria Kudus, Kudus.

Zarkasyi. D.S., 1991, "Metode Praktis Belajar Membaca Al-Qur'an", Yayasan Pendidikan Al-Qur'an Raudhatul Mujawwidin, Semarang 